\title{
Alkyl-Substituted Aminobis(phosphonates)_Efficient Precipitating Agents for Rare Earth Elements, Thorium, and Uranium in Aqueous Solutions
}

\author{
Emilia J. Virtanen, Siiri Perämäki, Kaisa Helttunen, Ari Väisänen,* and Jani O. Moilanen*
}

Cite This: ACS Omega 2021, 6, 23977-23987

Read Online

ABSTRACT: The efficient and environmentally sustainable separation process for rare earth elements (REE), especially for adjacent lanthanoids, remains a challenge due to the chemical similarity of REEs. Tetravalent actinoids, thorium, and traces of uranium are also present in concentrates of REEs, making their separation relevant. This study reports six simple water-soluble aminobis(phosphonate) ligands, $\mathrm{RN}\left[\mathrm{CH}_{2} \mathrm{P}(\mathrm{O})(\mathrm{OH})_{2}\right]_{2}(1 \mathrm{R}=$ $\mathrm{CH}_{2} \mathrm{CH}_{3}, 2 \mathrm{R}=\left(\mathrm{CH}_{2}\right)_{2} \mathrm{CH}_{3}, 3 \mathrm{R}=\left(\mathrm{CH}_{2}\right)_{3} \mathrm{CH}_{3}, 4 \mathrm{R}=$ $\left(\mathrm{CH}_{2}\right)_{4} \mathrm{CH}_{3}, 5 \mathrm{R}=\left(\mathrm{CH}_{2}\right)_{5} \mathrm{CH}_{3}, 6 \mathrm{R}=\mathrm{CH}_{2} \mathrm{CH}\left(\mathrm{C}_{2} \mathrm{H}_{5}\right)-$ $\left.\left(\mathrm{CH}_{2}\right)_{3} \mathrm{CH}_{3}\right)$ as precipitating agents for REEs, Th, and $\mathrm{U}$, as well as gives insight into the coordination modes of the utilized ligands with REEs at the molecular level. Aminobis(phosphonates) 4-6

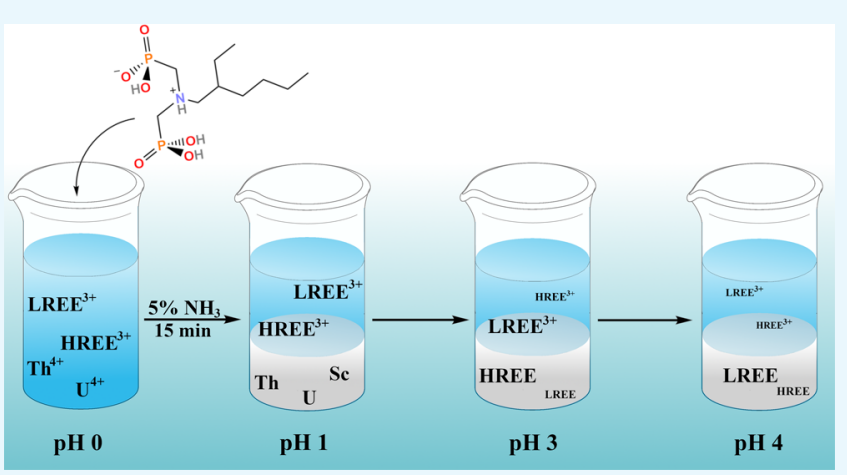
with longer carbon chains were found to separate selectively thorium, uranium, and scandium from REEs with short precipitation time $(15 \mathrm{~min})$ and excellent separation factors that generally range from 100 to 2000 in acidic aqueous solution. Ligands 1-6 also improved separation factors for adjacent lanthanoids in comparison to traditional oxalate precipitation agents. Importantly, precipitated metals can be recovered from the ligands with 3 molar $\mathrm{HNO}_{3}$ with no observed ligand decomposition enabling the possibility of recycling the ligands in the separation process. NMR-monitored $\mathrm{pH}$ titrations for 1 showed deprotonation steps at $\mathrm{p} K_{\mathrm{a}} 1.3,5.55$, and $>10.5$, which indicate that the ligands remain in a deprotonated $[\mathbf{L}]^{-1}$ form in the $\mathrm{pH}$ range of $0-4$ used in the precipitation studies. ${ }^{31} \mathrm{P}$ NMR titration studies between $\mathbf{1}$ and $\mathrm{M}\left(\mathrm{NO}_{3}\right)_{3}(\mathrm{M}=\mathrm{Y}, \mathrm{La}, \mathrm{Lu})$ gave satisfactory fits for 1:3, 1:2, and 1:1 metal-ligand stoichiometries for Y, La, and Lu, respectively, according to an F-test. Therefore, aminobis(phosphonate) precipitation agents $\mathbf{1 - 6}$ are likely to form metal complexes with fewer ligands than traditional separation agents like DEHPA, which coordinates to REEs in 1:6 metal-ligand ratio.

\section{INTRODUCTION}

Rare earth elements (REE) consisting of lanthanoids, scandium, and yttrium are widely used in crucial technological applications such as computers, catalysts, batteries of electric cars, and renewable energy production; latter two play an important role in a shift toward greener technologies. ${ }^{1}$ Thus, the demand of REEs has been estimated to increase considerably in the future. In EU alone, e-mobility and renewable energy production could increase the demand for dysprosium and neodymium up to 12 - and 4-fold by 2050 from the current demand of 200 and 4000 tons, respectively. ${ }^{2}$ Globally, the demand for all REEs has been estimated to grow annually $4.4 \%$ until 2026, raising concerns for the sufficiency of primary production of REEs from ores, which is not an environmentally sustainable process (see below). ${ }^{3}$ Ores of REEs also contain radioactive elements like thorium and uranium that complicate the separation process of REEs. ${ }^{4}$ Therefore, it is not only important to investigate the recycling and recovery of REEs from secondary sources, where the concentration of REEs is relatively high, ${ }^{5-7}$ but also to develop new separation processes for REE concentrates that allow the efficient and environmentally friendly separation of REEs from each other and other metals.

The most common separation process for lanthanoids includes liquid-liquid extraction with organophosphorous extracting agents, while $T h$ and $U$ are typically separated from lanthanoids first by selective dissolution and further purificated by liquid-liquid extraction. ${ }^{4}$ The most commonly used extracting agents for lanthanoids are di(2-ethylhexyl)phosphoric acid (DEHPA) and 2-ethylhexylphosphonic acid mono-2-ethylhexyl ester (EHEHPA) due to their robustness and good recyclability, whereas $\mathrm{Th}$ and $\mathrm{U}$ can be separated from REEs, and further from each other using tributylphos-

Received: June 7, 2021

Published: September 13, 2021 
phate (TBP) or secondary and tertiary amines. ${ }^{8}$ However, lanthanoids are chemically a very similar group of elements, and especially the separation of adjacent lanthanoids is challenging even with the commercial extracting agents. Although a liquid-liquid extraction process is the most suitable for industrial scale, one of the challenges has been to reduce the amount of used organic solvents to make the process more sustainable. ${ }^{4}$ The liquid-liquid extraction utilizing commercial extraction agents, such as DEHPA and EHEHPA, can be improved by replacing organic solvents with ionic liquids. ${ }^{9-13}$ This replacement has shown improvements in the separation of heavy and light adjacent lanthanoids, ${ }^{9,10}$ selectivity to $\mathrm{Nd}$ over transition metals, ${ }^{11}$ and high $\mathrm{La} / \mathrm{Ce}$ separation. $^{12}$ Ionic liquids have also been used in $\mathrm{Th} / \mathrm{U}$ separation with a success as very good separation factor is obtained $\left(\mathrm{SF}_{\mathrm{Th} / \mathrm{U}} 793\right) .{ }^{13}$ However, the high viscosity of ionic liquids still remains a challenge in the extraction processes.

Apart from the liquid-liquid extraction, separation for REEs and Th can also be done solely in water solution with no need for the organic phase, either by precipitation or fractional crystallization. Traditional precipitation agents, oxalates, have been reported to separate light lanthanoids from heavy ones by selective dissolution of rare earth oxalates. ${ }^{14}$ Fractional crystallization from water solutions with borates ${ }^{15}$ or coordination polymers ${ }^{16,17}$ have yielded good separation factors, especially for $\mathrm{Nd} / \mathrm{Dy}$ separation $\left(\mathrm{SF}_{\mathrm{Nd} / \mathrm{Dy}}>300\right)$. Furthermore, selective crystallization with the iodate-sulfate system has been reported to separate efficiently lighter lanthanoids from heavier ones, ${ }^{18}$ and selenite crystallization has yielded good Th/Ln separations. ${ }^{19}$ Nevertheless, the crystallization method with borates, iodate-sulfate, and selenite systems requires long reaction times of 5 days, hydrothermal conditions $(>453 \mathrm{~K})$, and in the case of borate systems, environmentally hazardous bromoform for the final separation step. ${ }^{15}$

Aminophosphonates have gathered attention in the medical field due to their pharmaceutical properties ${ }^{20}$ and good binding affinity toward medically relevant lanthanoids, such as gadolinium (common MRI contrasting agent) and samarium (nuclear medicine). ${ }^{21}$ Despite the good coordination properties of aminophosphonates toward REEs, their utilization in REE recovery and separation has been initiated only recently, yielding promising results. For example, the separation factors of (2-ethylhexylamino)methylphosphonic acid mono-2-ethylhexyl ester (HEHAMP) and 2-ethylhexyl-3(2-ethylhexylamino)pentan-3-yl-phosphonic acid (HEHAPP) in the liquid-liquid extraction process of REEs are larger in comparison to the separation factors of two conventional extracting agents, DEHPA and EHEHPA. ${ }^{22-26}$ Similarly, tetravalent $\mathrm{Th} / \mathrm{Ce}$ separation in a liquid-liquid extraction with an aminophosphonate-based extracting agent Cextrant 230 gives a good separation factor of $14.7 .^{27}$

Depending on the nature of organic moiety and the number of phosphonate groups in the aminophosphonate framework, aminophosphonates can be designed to be water soluble, ${ }^{28}$ which would enable their use as precipitation agents for metals in acidic aqueous solutions, similar to oxalates. ${ }^{20}$ Furthermore, by varying the number of phosphonate group and/or organic moiety, precipitation abilities of aminophosphonates toward different metal ions can be tuned. For example, by increasing the number of phosphonate groups in the ligand framework, more binding sites are available for metal ions in a single ligand. With that being said, we investigated the complexation and precipitation properties of simple aminobis(phosphonates) 1-6 (Scheme 1) toward REEs, Th and $U$ in

Scheme 1. General Synthesis Route for Aminomethylphoshonate Ligands 1-6

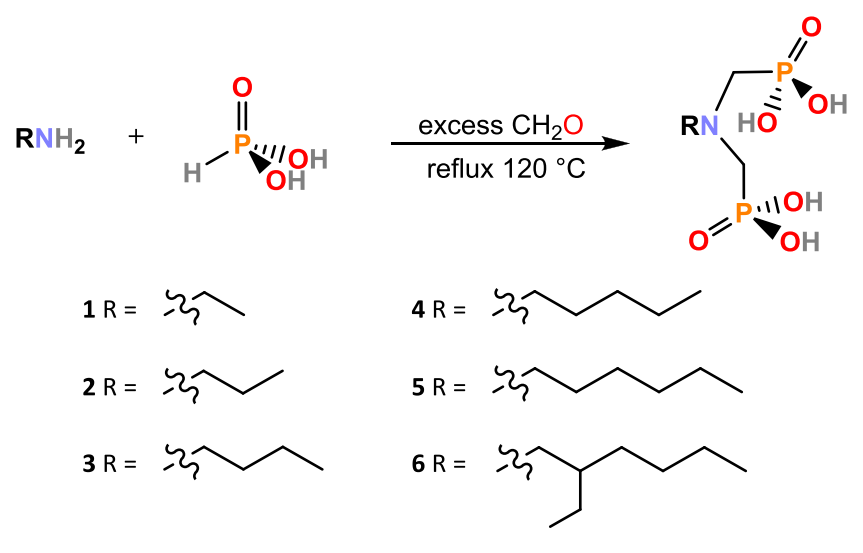

NMR, and larger $(\sim 100 \mathrm{mg})$ scale in different $\mathrm{pH}$ values ranging from 1 to 4 . We also determined the acid-base properties of synthesized aminobis(phosphonate) ligands utilizing NMR spectroscopy and carried out computational analysis for the most plausible complexes in the aqueous solution to get further insight into their solution behavior. To the best of our knowledge, this study demonstrates for the first time that simple aminobis(phosphonates), which can be synthesized by straightforward addition reactions, can be used as efficient precipitation agents with short precipitation times for REEs, Th, and $U$ in aqueous solutions.

\section{RESULTS AND DISCUSSION}

Ligands 1-6 were prepared using a modified reported one-pot synthesis, where a condensation reaction between an amine and formaldehyde is followed by nucleophilic addition of phosphorous acid under reflux condition in an acidic water solution (Scheme 1). ${ }^{28}$ Crude products were purified by recrystallization either from ethanol, water, or water:ethanol (2:1) mixture. The purity of the recrystallized products was ensured by ${ }^{1} \mathrm{H}$ NMR, IR, and elemental analysis (Figures S1S12).

As expected, the ligands with shorter carbon chains (1-3) showed higher solubility in water compared to ligands with longer (4 and 5) and branched (6) chains (Table S1). For example, the water solubility of ligands 1,3 , and 6 were 327, 184 , and $9.5 \mathrm{~g} / \mathrm{L}$, respectively.

Acid-Base Properties. The deprotonation processes of the most water-soluble ligand $\mathbf{1}$ were investigated to assess the protonation state of ligands in metal complexes. Dependence of the deprotonation steps of 1 on the $\mathrm{pH}$ was determined by NMR titrations in $\mathrm{D}_{2} \mathrm{O}$ at $295 \mathrm{~K}$. The $\mathrm{pH}$ of the $0.14 \mathrm{M}$ solution of 1 was adjusted between 0.5 and 10.5 with the addition of a $5 \% \mathrm{NH}_{3}$ solution, and ${ }^{31} \mathrm{P}$ and ${ }^{1} \mathrm{H}$ NMR spectra were measured at $0.5 \mathrm{pH}$ unit intervals. Figure S13 shows the measured ${ }^{31} \mathrm{P}$ NMR and ${ }^{1} \mathrm{H}$ NMR shifts as a function of $\mathrm{pH}$ for the $\mathrm{P}$ atom and $\mathrm{N}-\mathrm{CH}_{2}-\mathrm{P}$ protons, respectively. ${ }^{1} \mathrm{H} \mathrm{NMR}$ shifts of $\mathrm{OH}$ protons were not used in the determination since they cannot be directly observed in $\mathrm{D}_{2} \mathrm{O}$ due to the fast proton-deuterium exchange. Three equivalent points for the deprotonation steps of 1 were observed at $\mathrm{pH} \mathrm{1,} \mathrm{pH} \mathrm{5}$, and around $\mathrm{pH}$ 10. The observed shift for the first deprotonation is 
Scheme 2. Structures of Ligand 1 (L1) after Each Deprotonation Step

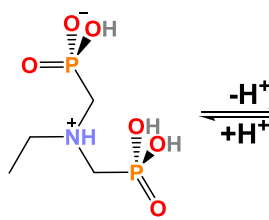

[L1]

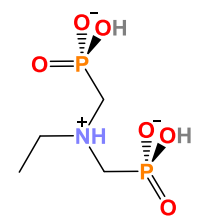

$[\mathrm{L} 1]^{-}$

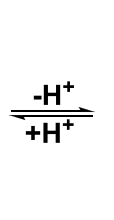

slightly different for ${ }^{31} \mathrm{P}$ nucleus than for the ${ }^{1} \mathrm{H}$ nuclei, but otherwise, the data obtained from ${ }^{31} \mathrm{P}$ and ${ }^{1} \mathrm{H}$ experiments are consistent. $\mathrm{p} K_{\mathrm{a}}$ values for the first two deprotonations were calculated from the observed chemical shifts according to a previously reported method. ${ }^{29}$ In contrast, the third deprotonation step at 10.5 takes place at the end of the titration $(\mathrm{pH}$ of ammonia is $\sim 10.6$ ). Thus, the $\mathrm{p} K_{\mathrm{a}}$ could not be calculated for the third deprotonation step. For the first and second deprotonation steps, the calculated $\mathrm{p} K_{\mathrm{a} 1}$ and $\mathrm{p} K_{\mathrm{a} 2}$ values are 1.33 and 5.55, respectively.

The deprotonation steps of $\mathbf{1}$ can be further elaborated by comparing the determined $\mathrm{p} K_{\mathrm{a}}$ values to the $\mathrm{p} K_{\mathrm{a}}$ values of two polyprotic phosphoric acids, namely pyrophosphoric acid $\left(\mathrm{p} K_{\mathrm{a} 1}=0.91, \mathrm{p} K_{\mathrm{a} 2}=2.10, \mathrm{pK}_{\mathrm{a} 3}=6.70 \text {, and } \mathrm{p} K_{\mathrm{a} 4}=9.32\right)^{30}$ and pamidronic acid $\left(\mathrm{p} K_{\mathrm{a} 1}=1.85, \mathrm{p} K_{\mathrm{a} 2}=5.85\right.$, and $\mathrm{p} K_{\mathrm{a} 3}=$ 10.30). ${ }^{31}$ Assuming that 1 exists as a zwitterion, the determined $\mathrm{p} K_{\mathrm{a} 1}$ value 1.33 suggests that the first deprotonation likely occurs from the fully protonated $\mathrm{P}(\mathrm{OH})_{2}(\mathrm{O})$ group forming structure $[\mathrm{L} 1]^{-}$(Scheme 2$)$, similar to pamidronic acid, which is known to exist as a zwitterion in a low $\mathrm{pH}$ regime. $^{32}$ The zwitterionic nature of $\mathbf{1}$ is further supported by the fact that it has only one low $\mathrm{p} K_{\mathrm{a}}$ value $(<2.50)$, arising from the deprotonation of one of the $\mathrm{P}(\mathrm{OH})_{2}(\mathrm{O})$ groups, in contrast to pyrophosphoric acid which has two low $\mathrm{p} K_{\mathrm{a}}$ values due to the two fully protonated $\mathrm{P}(\mathrm{OH})_{2}(\mathrm{O})$ groups. By comparing the $\mathrm{p} K_{\mathrm{a} 2}$ value (5.55) of 1 to the $\mathrm{p} K_{\mathrm{a} 3}(6.70)$ and $\mathrm{pK}_{\mathrm{a} 2}$ (5.85) values of pyrophosphoric acid and pamidronic acid, respectively, it can be concluded that the second deprotonation step originates from either of the $\mathrm{P}(\mathrm{OH})\left(\mathrm{O}^{-}\right)$ groups forming a twice deprotonated structure $[\mathrm{L} 1]^{2-}$. The third deprotonation step takes place either from the $\mathrm{P}(\mathrm{OH})$ $\left(\mathrm{O}^{-}\right)$or the $\mathrm{R}_{3} \mathrm{NH}^{+}$group. However, aminophosphonates have been reported to deprotonate first fully from the phosphorous groups before the $\mathrm{NH}^{+}$deprotonation is observed to occur. $^{31,33}$ Therefore, the third observed deprotonation is most likely to occur from the last $\mathrm{P}(\mathrm{OH})\left(\mathrm{O}^{-}\right)$proton forming a structure $[\mathrm{L1}]_{3}{ }^{-}$in $\mathrm{pH}>10.5$.

Complexation Studies. The binding affinity of ligand 1 toward REEs was investigated by performing NMR titrations in $\mathrm{D}_{2} \mathrm{O}$ with three different metal salts- $\mathrm{Y}\left(\mathrm{NO}_{3}\right)_{3}, \mathrm{La}\left(\mathrm{NO}_{3}\right)_{3}$, and $\mathrm{Lu}\left(\mathrm{NO}_{3}\right)_{3}$ - at low $\mathrm{pH}$ values $(\sim 1.4-2.4)$, where 1 exists as a monoanion. These metal salts were chosen because of their different ionic radii and diamagnetic nature (no unpaired electrons). NMR titrations were also attempted for $\mathbf{1}$ with $\mathrm{Sc}\left(\mathrm{NO}_{3}\right)_{3}$ and $\mathrm{Th}\left(\mathrm{NO}_{3}\right)_{4}$ by adding $1 \mathrm{mM}$ metal to $10 \mathrm{mM}$ ligand. Unfortunately, $\mathrm{Sc}$ and $\mathrm{Th}$ complexes of 1 precipitated out from $\mathrm{D}_{2} \mathrm{O}$ during titrations even at low $\mathrm{pH}$ values, preventing further analysis of the titration data.

First, metal-to-ligand titrations were carried out for $\mathrm{Y}$ by adding incremental amounts of $\mathrm{Y}\left(\mathrm{NO}_{3}\right)_{3}$ into $10 \mathrm{mM}$ solution of 1 in $\mathrm{D}_{2} \mathrm{O}$. After each addition of the metal salt, ${ }^{31} \mathrm{P}$ and ${ }^{1} \mathrm{H}$ NMR spectra were measured. The ${ }^{31} \mathrm{P}$ NMR spectrum of the free ligand displayed one triplet for the $\mathrm{P}$ atoms at $8.54 \mathrm{ppm}$, and the ${ }^{1} \mathrm{H}$ spectrum showed doublet, quartet, and triplet for
$\mathrm{N}-\mathrm{CH}_{2}-\mathrm{P}, \mathrm{C}-\mathrm{CH}_{2}-\mathrm{N}$, and $\mathrm{CH}_{3}$ protons, respectively. Since ${ }^{1} \mathrm{H}$ resonances overlapped strongly in metal-to-ligand (Figure S14) and also in reverse ligand-to-metal titrations (see below and Figure S15), the chemical shift change of the ${ }^{31} \mathrm{P}$ signal was followed. During the titration, the ${ }^{31} \mathrm{P}$ signal shifted 2.54 ppm upfield, indicating that the free ligand and complexed species experienced fast exchange dynamics on the NMR timescale (Figure S16). Saturation of the chemical shift changes of phosphorus was observed after the addition of 1 equiv of metal. However, when 1 was titrated with $\mathrm{La}$ and $\mathrm{Lu}$, smaller, <1 ppm upfield shift in ${ }^{31} \mathrm{P}$ signal was observed without saturation of the chemical shift changes at 1 equiv of metal (Figures S17 and S18). Additionally, the precipitate was observed during $\mathrm{Lu}$ titration; therefore, $\mathrm{pH}$ was set to 1.0 to prevent Lu complex from precipitating.

For $\mathrm{Y}$, analysis of the titration data to theoretical 1:1 and 1:2 $(\mathrm{M} / \mathrm{L})$ binding isotherms provided unsatisfactory fits with relatively large errors of fit (Figure S19), whereas the addition of a third binding constant $\mathrm{K}_{3}$ for the 1:3 binding model improved the fit significantly (Figure 1). Data was also fitted to

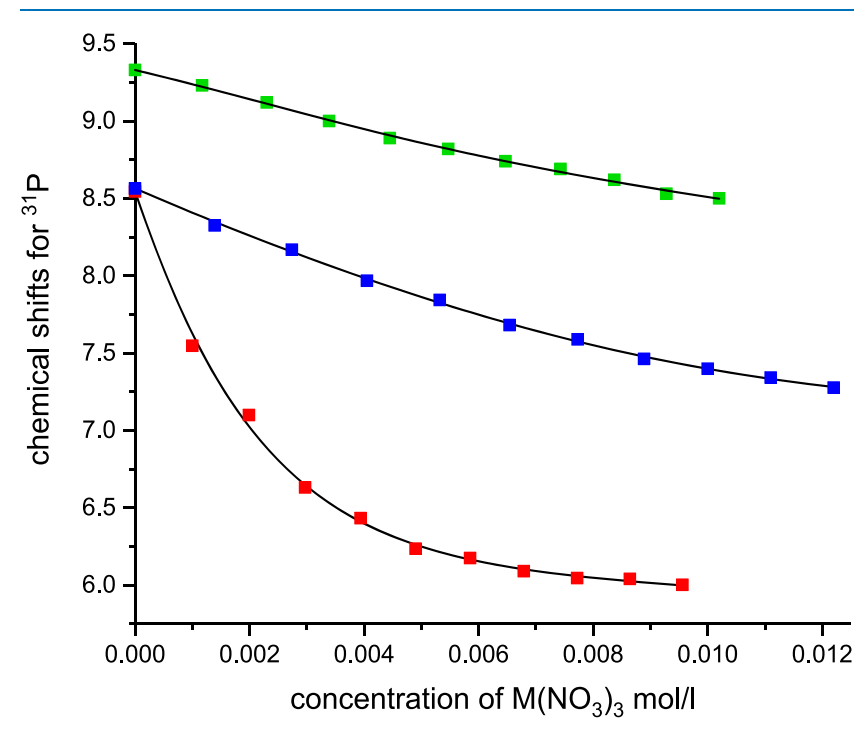

Figure 1. ${ }^{31} \mathrm{P}$ NMR shift changes as a function of the concentration of $\mathrm{M}\left(\mathrm{NO}_{3}\right)_{3}$ when ligand $\mathbf{1}$ is titrated with $\mathrm{Y}\left(\mathrm{NO}_{3}\right)_{3}$ (red) and $\mathrm{La}\left(\mathrm{NO}_{3}\right)_{3}$ at $\mathrm{pH} 1.8$ (blue), and $\mathrm{Lu}\left(\mathrm{NO}_{3}\right)_{3}$ at $\mathrm{pH} 1.0$ (green). Fittings for $1: 3,1: 2$, and $1: 1(\mathrm{M} / \mathrm{L})$ binding models are presented for $\mathrm{Y}, \mathrm{La}$, and $\mathrm{Lu}$, respectively (black solid lines).

a theoretical 1:4 binding isotherm (Figure S19). Because a small improvement of fit was observed by introducing more variables to the model, statistical F-tests were carried out for all fits to assign the preferential binding model. Based on the Ftests, the 1:3 binding model provided the best fit for the titration data at this range of concentrations for Y (Table S2). Similar fits to theoretical $1: 1,1: 2,1: 3$, and $1: 4$ binding isotherms were obtained for La as for Y (Figures 1 and S20); 
however, the F-tests indicated that the 1:2 binding model was slightly better than the 1:3 model (Table S3). Interestingly, for $\mathrm{Lu}$, analysis of the titration data to a theoretical 1:1 binding isotherm already provided a satisfactory fit (Figures 1 and S20), which was confirmed by the F-test (Table S4). The binding constants obtained for the $1: 1,1: 2$, and $1: 3$ metal complexes (Table 1 ) indicate that all $\mathrm{M} / \mathrm{L}$ complexes are being formed in the solution when the ligand is titrated with Y or La.

Table 1. Overall Logarithmic Binding Constants $(\log K)$ for 1:1, 1:2, and 1:3 (Metal:Ligand) Binding Models ${ }^{a}$

$\begin{array}{llll} & \log K 1: 1 & \log K 1: 2 & \log K 1: 3 \\ \mathbf{Y}_{\mathrm{ML}} & 2.4 \pm 0.2 & 4.9 \pm 0.4 & 7.3 \pm 0.6 \\ \mathbf{Y}_{\mathrm{LM}} & 2.6 \pm 0.2 & 4.4 \pm 0.4 & 6.7 \pm 0.7 \\ \mathbf{L a}_{\mathrm{ML}} & 2.6 \pm 0.5 & 4.4 \pm 0.1 & \\ \mathbf{L a}_{\mathrm{LM}} & 2.7 \pm 0.5 & 4.3 \pm 0.4 & 6.8 \pm 0.3 \\ \mathbf{L u}_{\mathrm{ML}} & 2.1 \pm 0.3 & & \\ \mathbf{L u} & \text { N.D. } & & \end{array}$

${ }^{a} \mathrm{M}_{\mathrm{ML}}$ represents the metal-to-ligand titration and $\mathrm{M}_{\mathrm{LM}}$ the ligand-tometal titration $(\mathrm{M}=\mathrm{Y}, \mathrm{La}, \mathrm{Lu})$. Errors are derived from standard deviation. ${ }^{b}$ Sample formed a gel.

Reverse ligand-to-metal titrations were also performed by titrating $10 \mathrm{mM} \mathrm{M}\left(\mathrm{NO}_{3}\right)_{3}$ with incremental addition of 1 . However, the addition of 3 equiv of 1 to the NMR tube containing $\mathrm{Lu}\left(\mathrm{NO}_{3}\right)_{3}$ promoted the formation of a gel-like structure, thus preventing the determination of the binding constant for Lu. For Y and La, the first spectra were recorded after the addition of 0.3 eq of ligand, where phosphorus nuclei resonated at 6.25 and $7.02 \mathrm{ppm}$ for $\mathrm{Y}$ and La, respectively (Figures S21 and S22). The titration was continued until the concentration of 1 reached 5 equiv, at which point, the chemical shift of the phosphorus signal had changed to 8.16 ppm for $Y$ and $8.25 \mathrm{ppm}$ for La without saturation of the chemical shift changes.

Analysis of the titration data to a 1:1 binding model provided unsatisfactory fits for both $\mathrm{Y}$ and La, whereas the addition of $1: 2$ and 1:3 binding models showed a slight improvement to the fits (Figures 2, S23, and S24). Similarly, to

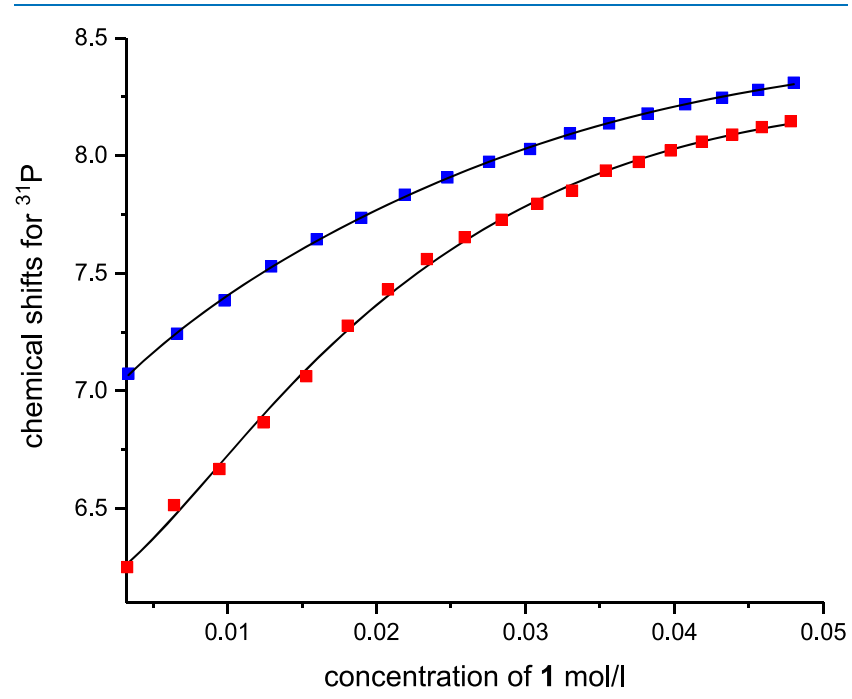

Figure 2. ${ }^{31} \mathrm{P}$ NMR shift change as a function of the concentration of 1 when $\mathrm{Y}\left(\mathrm{NO}_{3}\right)_{3}$ (red) and $\mathrm{La}\left(\mathrm{NO}_{3}\right)_{3}$ (blue) are titrated with 1 . Fittings for 1:3 (M/L) binding models are presented as black lines. the metal-to-ligand titration, fourth binding constant $\mathrm{K}_{4}$ was also fitted to the titration data of $\mathrm{Y}$ and La where it provided the best fit for one of the repeats in both cases (Tables S5 and S6). Based on the unsaturation observed in the titration data and partial success in the fitting of the 1:4 model, it is possible that higher-order complexes are formed in the solution when the concentration of the ligand is high enough. Overall, the binding constants obtained from the reverse ligand-to-metal titrations are similar to the metal-to-ligand binding constants for $\mathrm{Y}$ and La, although small differences can be observed (Table 1). The differences most likely arise from the different forming order of the complexes in the titrations, as in the reverse ligand-to-metal titration, the $1: 1$ complex forms first followed by the 1:2 and 1:3 complexes.

Proposed complexation structures based on the titrations for $\mathrm{Y}, \mathrm{La}$, and $\mathrm{Lu}$ complexes are illustrated in Scheme 3. As the $\mathrm{pH}$ was between 1.4 and 2.4 during titrations, 1 is expected to coordinate to the metals in the deprotonated $[\mathrm{L1}]^{-1}$ form (Scheme 2), which is the most likely form of $\mathbf{1}$ at the lower $\mathrm{pH}$ region. This protonation state also provides neutral 1:3 complexes.

Further insight into the coordination properties of ligands was obtained from the density functional theory calculations, which were carried out for the 1:3 complex of $\mathrm{Y}^{3+}$ and three $[\mathbf{L}]^{-}\left(\mathbf{L}=\mathrm{CH}_{3} \mathrm{~N}\left[\mathrm{CH}_{2} \mathrm{P}(\mathrm{O})(\mathrm{OH})_{2}\right]_{2}\right)$ in the neutral and zwitterionic form in the solution state. The calculations predicted the zwitterionic form to be significantly more stable $\left(76 \mathrm{~kJ} \mathrm{~mol}^{-1}\right.$ ) than the neutral one, which is consistent with the NMR studies. As illustrated with the space-filling model of the most stable optimized 1:3 complex, three $[\mathbf{L}]^{-}$ligands do not entirely complete the coordination sphere of $\mathrm{Y}^{3+}$ (Figure S25). Thus, it is likely that in the aqueous solution coordinated water molecules and/or other species present in the solution might coordinate $\mathrm{Y}^{3+}$ ion in 1:3 complex. The results further support that 1:4 complexes cannot be fully ruled out due to steric reasons, although 1:3 complexes are the most likely species in the aqueous solution at least for the REEs with larger ionic radii based on the NMR studies.

The 1:3 M/L stoichiometry proposed for M:1 complexes was compared with other phosphonate-metal complexes reported in the literature. The 1:3 metal-ligand stoichiometry has also been reported for the complexes of lanthanoids and nitrilotris(methylphosphonic acid), whereas commercial extraction agent DEHPA, which contains only one phosphonate group, forms 1:6 complexes with REEs and actinoids. ${ }^{34-37}$ Although NMR titration data with Th could not be analyzed, the literature suggests that bisphosphonates bind into Th and U either with similar $1: 3$ or $1: 2$ stoichiometry, and depending on the medium, nitrate or sulfate ions fulfill the coordination sphere. ${ }^{38-42}$ As uranium is commonly precipitated as an ammonium salt by injecting $\mathrm{NH}_{3}$ and $\mathrm{CO}_{2}$ gases into a uranium-containing solution, it is therefore highly possible for uranium to also form insoluble ammonium salts at higher $\mathrm{pH}$ values. $^{43,44}$ Also, Th forms insoluble ammonium salts in the solution with higher $\mathrm{pH}$ (see below). Taken together, the obtained results indicate that a smaller amount of 1-6 is needed for the REE separation process compared to the commercial liquid-liquid extraction (DEHPA and EHEHPA), which form 1:6 complexes with REEs. ${ }^{34-37}$ On the other hand, commercial precipitation agents (oxalates) are needed in smaller quantities than ligands $\mathbf{1 - 6}$ since oxalates have been reported to bind with 2:3 metal-ligand ratio. ${ }^{45,46}$ 
Scheme 3. Proposed Zwitterionic Structures for 1:1, 1:2, and 1:3 M/L Metal Complexes $(M=$ Y, La, Lu) with Ligand 1
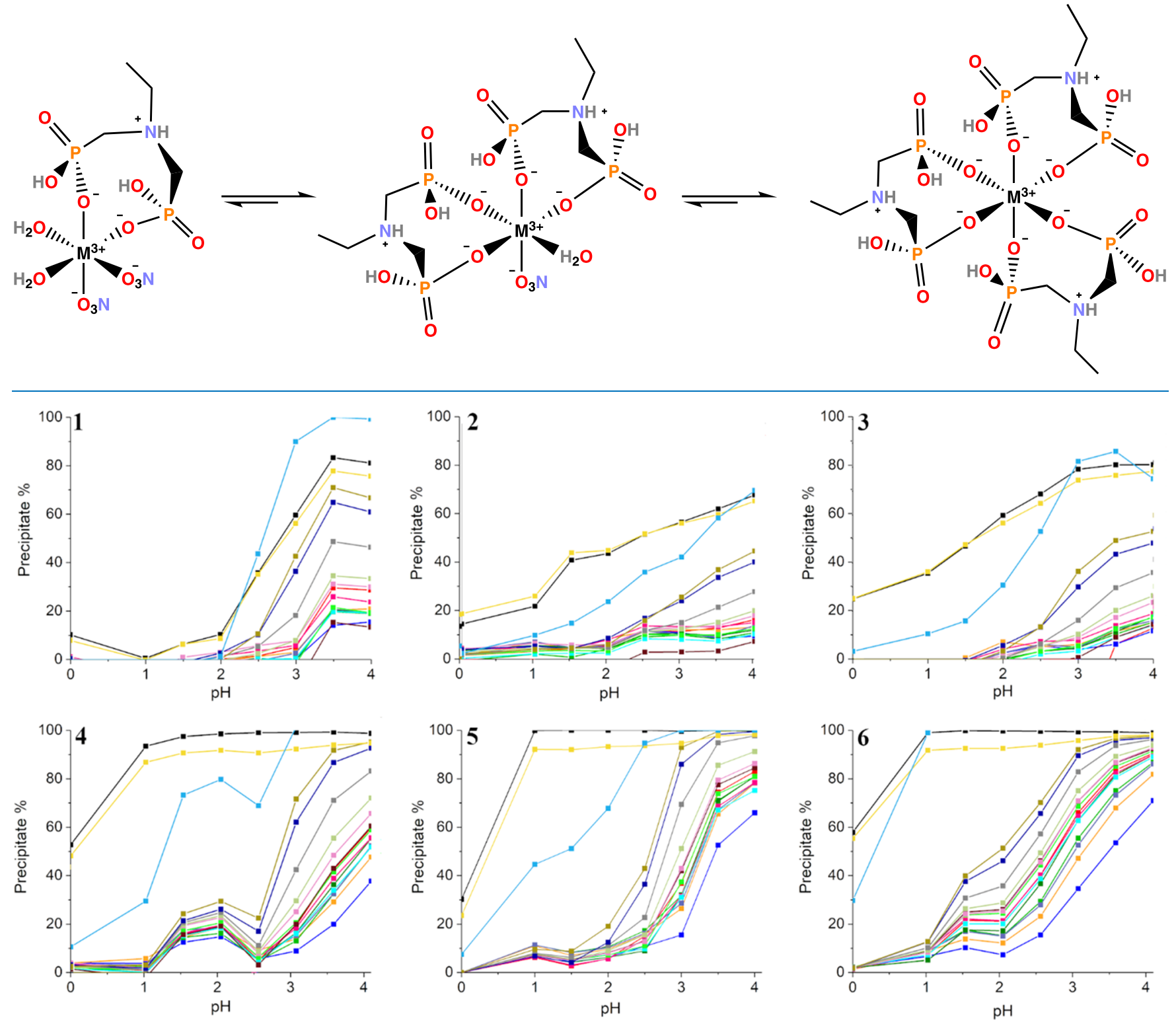

Figure 3. Precipitation percentages of REEs, Th, and $\mathrm{U}$ in different $\mathrm{pH}$ for ligands $\mathbf{1 - 6}$ (from the top left to the bottom right). For clarity, the error bars are omitted from the figure, but the standard deviation errors for precipitation percentages are given in Tables S8-S13.

Precipitation Studies. The precipitation properties of ligands 1-6 toward REEs, Th, and $\mathrm{U}$ in $5 \% \mathrm{HNO}_{3}$ solution were investigated in a $\mathrm{pH}$ range of $0-4$. The $\mathrm{pH}$ was not increased above 4 to avoid precipitation of lanthanoid hydroxides. ${ }^{47} \mathrm{pH}$ was set with $5 \% \mathrm{NH}_{3}$ solution and the precipitation percentages were determined by taking into account the dilution of the added base, calculating the precipitated amount for each metal, and dividing the precipitated amount by the concentration at the beginning. As the expected stoichiometry for the metal-ligand ratio is $1: 3$, solutions were prepared with a 6-fold excess of the ligands to ensure sufficient amount of the precipitation agents. From each $\mathrm{pH}$, the sample was taken aside, filtrated, and diluted with 5\% $\mathrm{HNO}_{3}$ for the inductively coupled plasma optical emission spectrometer (ICP-OES) measurements. Precipitation studies were also performed without the presence of ligands to ensure that the metal complexes do not precipitate out from the solution as ammonia salts (Table S7). No precipitation or minimal precipitation was observed for REEs and $U$ with ammonia, whereas $\mathrm{Th}$ precipitated out from the solution at $\mathrm{pH}$ higher than 2.5 .

Figure 3 shows the precipitated percentages for ligands 1-6 in the $\mathrm{pH}$ range of $0-4$, and five main trends can be observed from it. First, the deprotonated form of ligand $[\mathbf{L}]^{-}$increases when the $\mathrm{pH}$ of the solution increases, resulting in higher precipitation percentages of REEs, Th, and U. Second, ligands 4-6 with longer carbon chains precipitate more metals out from the solution than 1-3 with shorter carbon chains, with the exception of ligand $\mathbf{1}$, which unexpectedly precipitates out more some of the metals $(\mathrm{Er}-\mathrm{Lu}, \mathrm{Th}$, and $\mathrm{U})$ than ligands 2 and 3. Third, ligand 6 precipitates $U, T h$, and Sc selectively at $\mathrm{pH} 1$ leaving all of the lanthanoids and $\mathrm{Y}$ in the solution. 


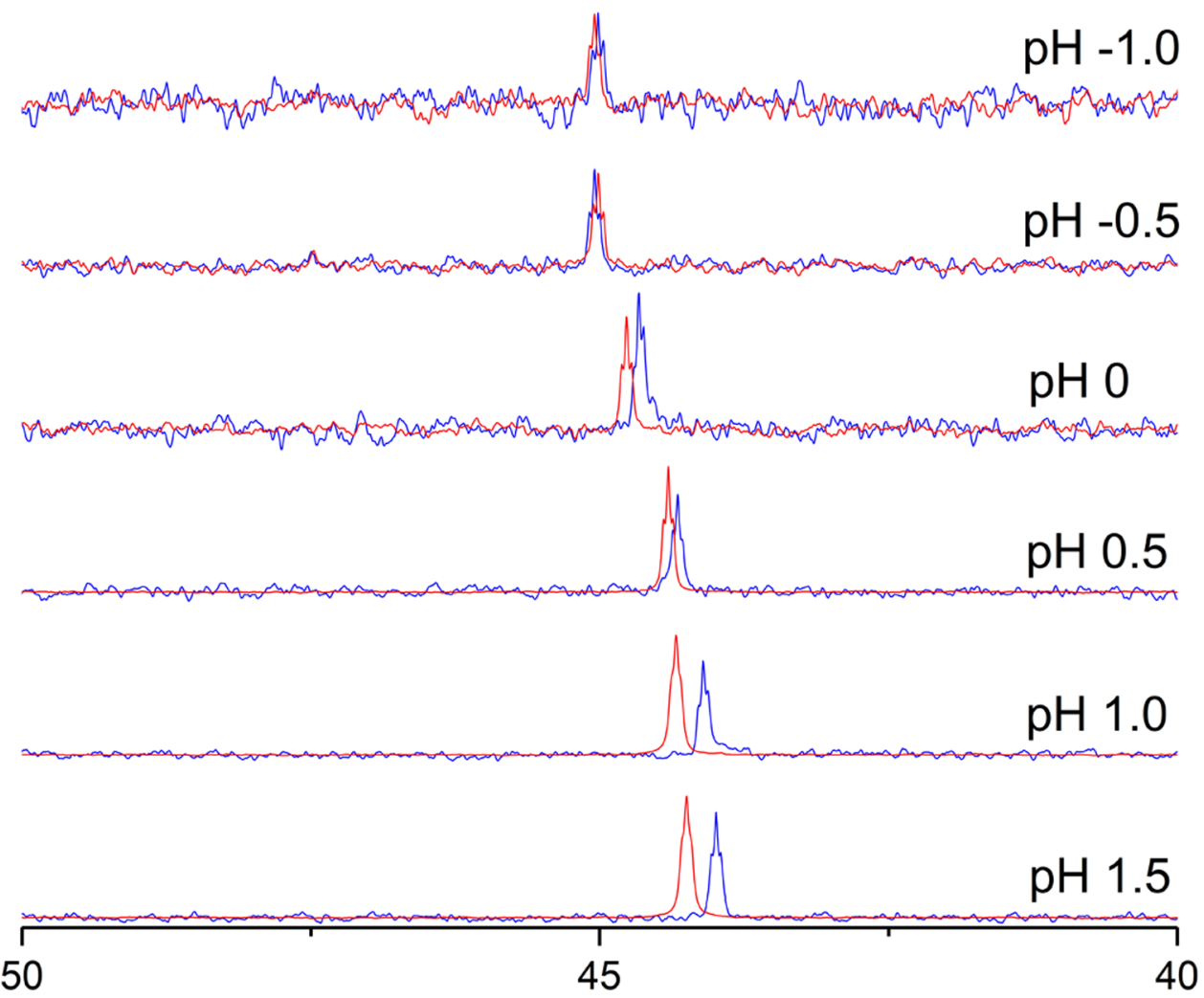

Figure 4. Three hundred megahertz ${ }^{31} \mathrm{P}$ NMR spectra of ligand $1 \mathrm{Y}$ complex (blue) and free ligand $\mathbf{1}$ (red) in different $\mathrm{pH}$ values.

Fourth, ligands $\mathbf{4}$ and $\mathbf{5}$ are also selective precipitating agents for $\mathrm{Sc}$ and $\mathrm{Th}$ over other investigated REEs at $\mathrm{pH} 1$, but a decrease in the $U$ precipitation rate can be observed when compared to ligand 6 . Fifth, with ligand 4, a dip in the precipitation percentages for most of the metals can be observed at $\mathrm{pH} 2.5$, which is most likely resulting from the metal complexes dissolving back into the solution.

Separation Factors. The ability to separate two elements from each other is expressed by separation factor $(S F)$, which is calculated by adapting calculations from a liquid-liquid extraction as presented by Nelson et al. $^{48}$ The ratio of precipitated metals and metals left in the solution on each $\mathrm{pH}$ is expressed as $D$ (distribution factor) and can be determined according to the following eq 1 , where $[\mathrm{M}]_{\mathrm{p}}$ expresses the precipitated metals and $[\mathrm{M}]_{\mathrm{s}}$ the metals in solution.

$$
D=\frac{[\mathrm{M}]_{\mathrm{p}}}{[\mathrm{M}]_{\mathrm{s}}}
$$

Separation factors between two elements can be determined with eq 2 by comparing their distribution factors.

$$
\mathrm{SF}_{1 / 2}=\frac{D_{1}}{D_{2}}
$$

If metals precipitate completely from the solution or reversely, no precipitation occurs, it is not possible to determine the distribution factor and separation factor for the metal. Separation factors between adjacent lanthanoids, Sc, $\mathrm{Th}$, and $\mathrm{U}$ were calculated for all of the ligands 1-6 (Tables S14-S19). Ionic radius (3+) of Y lies between the radii of Er and $\mathrm{Tm}$, and therefore, $\mathrm{Y}$ was positioned between these two elements.
All ligands 16 have almost equal ability to separate adjacent lanthanoid pairs at each $\mathrm{pH}$, meaning that no ligand was considerably better than the other. Additionally, separation factors between heavy adjacent lanthanoids from $\mathrm{Er}$ to $\mathrm{Lu}$ are calculated to be slightly better for all of the ligands 1-6 when compared to other adjacent lanthanoid pairs. For example, the best value for heavy lanthanoid pairs $S F_{\mathrm{Tm} / \mathrm{Yb}}$ and $S F_{\mathrm{Yb} / \mathrm{Lu}}$ arecalculated to be $4.33 \pm 0.04$ and $2.32 \pm 0.02$ with ligands 5 and 4 , respectively. These separation factors are higher than the reported separation factors for DEHPA and EHEHPA $\left(S F_{\mathrm{Tm} / \mathrm{Yb}}=1.12-2.12, S F_{\mathrm{Yb} / \mathrm{Lu}}=1.03-1.44\right)$ in the conventional liquid-liquid separation processes. ${ }^{4}$ For lighter lanthanoids separation factors are generally under two for the adjacent lanthanoids, with the exception of ligand 4 which has separation factor of $3.81( \pm 0.86)$ for Ce/La separation, which is in the same range with the conventional liquid-liquid method $\left(S F_{\mathrm{Ce} / \mathrm{La}} 1.30-4.55\right)$, but shows improvement to the previously reported fractional crystallization with borates ${ }^{15}$ $\left(S F_{\mathrm{Ce} / \mathrm{La}} 1.43\right)$ or oxalates ${ }^{49}\left(S F_{\mathrm{Ce} / \mathrm{La}} 1.5-2.5\right)$. With ligand 5, albeit the obtained $S F_{\mathrm{Ce} / \mathrm{La}}$ is lower, $2.11 \pm 0.21$, it is still in par with other separation systems reported above. For the other adjacent lanthanoids ( $\mathrm{Nd}-\mathrm{Er})$, separation factors are calculated to be rather low for all of the ligands as they range from 1 to 1.7. When compared to other precipitation agents such as oxalates, the ligands 1-6 perform either similarly or slightly better, for example $S F_{\mathrm{Nd} / \mathrm{Sm}}$ of 1.6 has been reported for oxalates, ${ }^{49}$ whereas for ligand $\mathbf{5}$, a slightly better value is obtained $\left(S F_{\mathrm{Nd} / \mathrm{Sm}} 2.0 \pm 0.1\right)$. Compared to the hydrothermal borate crystallization, ligands 16 perform either similar or worse. However, a notable fact is that the borate crystallization requires high temperatures of $473 \mathrm{~K}$ for 3 days and additional 2 days for slow crystallization, ${ }^{15}$ whereas the precipitation of REEs and studied actinoids takes only $15 \mathrm{~min}$ at $295 \mathrm{~K}$ in 
acidic water solutions. As $\mathrm{Y}$ is positioned between Er and Tm, separation factors between these elements were also calculated. Good separation factors can be calculated for all of the ligands 16 for $\mathrm{Tm} / \mathrm{Y}$ separation ranging from 2.06 to 8.88 , of which the highest separation factor is obtained with ligand $\mathbf{1}$. Smaller separation values $(1.00-3.33)$ are obtained for $\mathrm{Er} / \mathrm{Y}$ separation, the highest one $(3.33 \pm 1.17)$ is observed for ligand 3.

Overall best separation factors are obtained when distribution factors of Sc, Th, or $\mathrm{U}$ are compared to the distribution factors of lanthanoids, for example, with ligand $\mathbf{5} S F_{\mathrm{Sc} / \mathrm{La}}$ is calculated to be over 15000 at $\mathrm{pH} 1$ as Sc precipitates out from the solution almost quantitatively. In fact, with ligands 46, SF cannot be calculated for Sc in most cases as it completely precipitates from the solution already at a low $\mathrm{pH}$ value $(\mathrm{pH}$ 1-2.5). Similar results are obtained for $U$ and $T h$. For example, $S F_{\mathrm{Th} / \mathrm{Lu}}$ is calculated to be $44.41 \pm 6.34,48.32 \pm 6.04$, and $33.62 \pm 32.13$ for ligands 4-6, respectively, at low $\mathrm{pH}$ (22.5). These $S F_{\mathrm{Th} / \mathrm{Lu}}$ are similar to $S F_{\mathrm{Th} / \mathrm{Ln}}$ obtained from the fractional $\mathrm{SeO}_{2}$ crystallization in hydrothermal conditions. ${ }^{19} \mathrm{U}$ precipitates completely from the solution with 6 at $\mathrm{pH} 1$ and no separation factor can be calculated for $\mathrm{U} / \mathrm{Lu}$ separation, whereas with 4 and 5 , the best separation factors are $9.45 \pm$ 1.26 and $23.79 \pm 0.24$, respectively.

In general, ligands $\mathbf{1 - 6}$ provide improved separation factors in mild conditions especially for heavy adjacent lanthanoids and $\mathrm{Y}$, when compared to oxalates or liquid-liquid extracting agents, and excellent selectivity toward Sc, Th, and $U$ is observed with ligands 4-6. Even though separation factor-wise the system is no better than the fractional crystallization with borates, the advantage is the simple and fast precipitation of the metals directly from the water solution at $295 \mathrm{~K}$.

Ligand and Metal Recovery. Recovery of the ligands was investigated with the 1:3 complex of $\mathrm{Y}^{3+}$ and ligand $\mathbf{1}$ by measuring ${ }^{31} \mathrm{P}$ NMR shifts of the complex in low $\mathrm{pH}$ values $(1.5-(-1))$ set with $65 \% \mathrm{HNO}_{3}$, and comparing spectra to the NMR spectra of free ligand. It can be observed from Figure 4 that 1 is substituted for $\mathrm{NO}_{3}{ }^{-}$around $\mathrm{pH}-0.5$ because the ${ }^{31} \mathrm{P}$ NMR shift of the Y-containing sample matches the shift of the free ligand $\mathbf{1}$ at this $\mathrm{pH}$.

Importantly, no decomposition of the ligand can be observed in the ${ }^{1} \mathrm{H}$ NMR spectrum of ligand during the recovery process. As the molarity of nitric acid in $\mathrm{pH}-0.5$ can be calculated to be 3 molar, these findings not only show that the precipitated metals can be recovered from the complexes with 3 molar $\mathrm{HNO}_{3}$, but they also indicate that the investigated ligands $\mathbf{1 - 6}$ are recyclable and could be utilized more than once in the separation process.

\section{CONCLUSIONS}

NMR and large-scale complexation and precipitation studies were performed for six different simple aminobis(phosphonates) ligands 1-6 with REEs, Th, and U. These studies were complemented by quantum chemical calculations and the acid-base titration in NMR scale to determine the protonation steps of the utilized ligands. The determined $\mathrm{p} K_{\mathrm{a}}$ values of 1.3 and 5.6 for 1 suggested that 1-6 exist mainly as monoanionic $\left([\mathbf{L}]^{-}\right)$form in the $\mathrm{pH}$ range used in the complexation and precipitation studies, whereas NMR titration studies in conjunction with computational data indicated that 1-6 preferably form either $1: 1,1: 2$, or 1:3 (metal-ligand) complexes in zwitterionic form with $\mathrm{Lu}, \mathrm{La}$, and $\mathrm{Y}$, respectively. $\log K$ values for $1: 1,1: 2$, and 1:3 complexes, respectively, are calculated to be $2.4 \pm 0.2,4.9 \pm 0.4$, and $7.3 \pm 0.3$ for $Y, 2.6 \pm$ 0.5 and $4.4 \pm 0.1$ for $\mathrm{La}$, and $2.1 \pm 0.3$ for $\mathrm{Lu}$, in aqueous acidic solutions. Importantly, the precipitation studies showed that 4-6 are very selective precipitation agents to recover radioactive elements ( $T h$ and $U$ ) from REE concentrates in a short period of time $(15 \mathrm{~min})$. The performance of $1-6$ to separate adjacent lanthanides was comparable or in some cases more efficient compared to other precipitation methods (borates and oxalates) reported so far. Additionally, the precipitation agents are recyclable in the separation process, as shown by the NMR study, and the metals could be recovered from the ligands by dissolving the formed complexes to 3 molar $\mathrm{HNO}_{3}$ without any decomposition of the ligands 1-6. Considering all the abovementioned and the fact that aminobis(phosphonates) are relatively easy to synthesize with simple addition reaction, aminobis(phosphonates) are promising precipitation agents for REEs, Th, and $U$. Importantly, the selectivity of aminobis(phosphonates) toward adjacent lanthanoids could be increased by modification of ligand frameworks, which underpin their potential as alternative precipitation agents.

\section{EXPERIMENTAL SECTION}

Materials and Methods. Formaldehyde (36\%) was purchased from VWR; phosphorous acid (99\%) and hexylamine (98\%) from Fluka Chemical Co.; 2-ethylhexylamine (98\%), $\mathrm{La}\left(\mathrm{NO}_{3}\right)_{3} \cdot 6 \mathrm{H}_{2} \mathrm{O}$, and propylamine hydrochloride from Sigma-Aldrich; ethylamine hydrochloride (98\%), butylamine (99\%), and $\mathrm{Y}\left(\mathrm{NO}_{3}\right)_{3} \cdot 6 \mathrm{H}_{2} \mathrm{O}$ (99.8\%) from Merck; and $\mathrm{Lu}\left(\mathrm{NO}_{3}\right)_{3} \cdot \mathrm{H}_{2} \mathrm{O}$ from abcr and amylamine (98\%) from TCI chemicals. All of the chemicals were reagent grade and used without further purification. NMR measurements and titrations were performed on a Bruker Avance III $300 \mathrm{MHz}$ spectrometer, and NMR data was processed with Bruker TopSpin 4.0.8. IR spectra were measured by Bruker Alpha FTIR. Elemental analyses were done by an Elementar Vario EL III-analysator. Lanthanoid concentrations were determined by a Perkin Elmer Optima 8300 DV ICP-OES- spectrometer.

Syntheses. [(Ethylimino)bis(methylene)]bis(phosphonic acid) (1) was synthesized by dissolving phosphorous acid $(19.35 \mathrm{~g}, 0.24 \mathrm{~mol})$ and ethylamine $(10.1 \mathrm{~g}, 0.05 \mathrm{~mol})$ into a mixture of $100 \mathrm{~mL}$ of deionized water and $100 \mathrm{~mL}$ of $37 \%$ $\mathrm{HCl}$. An excess of $36 \%$ formaldehyde $(36 \mathrm{~mL}, 0.48 \mathrm{~mol}$ ) was added dropwise to the solution for an hour, after which the solution was refluxed overnight at $120{ }^{\circ} \mathrm{C}$. The solvent was removed under vacuum resulting in an oily product of which 1 was precipitated out with ethanol. The crude product was purified by recrystallization from hot ethanol to obtain it as a white solid. Yield $12.81 \mathrm{~g}, 46 \% .{ }^{1} \mathrm{H}$ NMR $\left(\mathrm{D}_{2} \mathrm{O} 300 \mathrm{MHz}\right): \delta$ 3.65-3.51 $(\mathrm{m}, 6 \mathrm{H})$, and $1.39(\mathrm{t}, 3 \mathrm{H}) .{ }^{31} \mathrm{P}$ NMR $\left(\mathrm{D}_{2} \mathrm{O} 300\right.$ $\mathrm{MHz}): \delta 8.90$. Elemental analysis Calcd for $\mathrm{C}_{4} \mathrm{H}_{13} \mathrm{NO}_{6} \mathrm{P}_{2}: \mathrm{N}$, 6.01; C, 20.61; and H, 5.62. Found: C, 20.42; H, 5.68; and N, 5.92.

[(Propylimino)bis(methylene)]bis(phosphonic acid) (2) was prepared following the same procedure. The solvent was removed under vacuum resulting in a pale yellow oily product. A white precipitate was obtained after adding ethanol and heating up the solution. The crude product was purified by recrystallization from hot ethanol. Yield $7.27 \mathrm{~g}, 46 \% .{ }^{1} \mathrm{H}$ NMR $\left(\mathrm{D}_{2} \mathrm{O} 300 \mathrm{MHz} \delta\right): 3.60(\mathrm{~d}, 4 \mathrm{H}), 3.51(\mathrm{~m}, 2 \mathrm{H}), 1.84(\mathrm{~m}, 2 \mathrm{H})$, and $1.02(\mathrm{t}, 3 \mathrm{H}) .{ }^{31} \mathrm{P}$ NMR $\left(\mathrm{D}_{2} \mathrm{O} 300 \mathrm{MHz}\right): \delta 8.79$. Elemental analysis calcd for $\mathrm{C}_{5} \mathrm{H}_{15} \mathrm{NO}_{6} \mathrm{P}_{2}: \mathrm{C}, 24.3 ; \mathrm{H}, 6.12$; and N, 5.67. Found: C, 24.3; H, 6.00; and N, 5.78. 
[(Butylimino)bis(methylene)]bis(phosphonic acid) (3) was prepared following the same procedure. The solvent was removed under vacuum resulting in a yellow oily product. A white precipitate was obtained from adding ethanol and heating the solution. The crude product was purified by recrystallization from the water-ethanol solution. Yield $6.51 \mathrm{~g}$, $41 \% .{ }^{1} \mathrm{H}$ NMR $\left(\mathrm{D}_{2} \mathrm{O} 300 \mathrm{MHz}\right): \delta 3.66-3.53(\mathrm{~m}, 6 \mathrm{H}), 1.83$ $(\mathrm{m}, 2 \mathrm{H}), 1.46(\mathrm{~m}, 2 \mathrm{H})$, and $1.01(\mathrm{t}, 3 \mathrm{H}) .{ }^{31} \mathrm{P}$ NMR $\left(\mathrm{D}_{2} \mathrm{O} 300\right.$ $\mathrm{MHz}): \delta$ 8.65. Elemental analysis calcd for $\mathrm{C}_{6} \mathrm{H}_{17} \mathrm{NO}_{6} \mathrm{P}_{2}: \mathrm{C}$, 27.6; H, 6.56; and N, 5.36. Found: C, 27.1; H, 6.46; and N, 5.43 .

[(Pentylimino)bis(methylene)]bis(phosphonic acid) (4) was prepared following the same procedure. The product precipitated out after cooling down. The white crude product was purified by recrystallization from water. Yield $5.83 \mathrm{~g}, 31 \%$. ${ }^{1} \mathrm{H}$ NMR $\left(\mathrm{D}_{2} \mathrm{O} 300 \mathrm{MHz}\right): \delta 3.66-3.52(\mathrm{~m}, 6 \mathrm{H}), 1.85(\mathrm{~m}$, $2 \mathrm{H}), 1.41(\mathrm{~m}, 4 \mathrm{H})$, and $0.96(\mathrm{t}, 3 \mathrm{H}) .{ }^{31} \mathrm{P}$ NMR $\left(\mathrm{D}_{2} \mathrm{O} 300\right.$ $\mathrm{MHz}): \delta$ 8.56. Elemental analysis calcd for $\mathrm{C}_{7} \mathrm{H}_{19} \mathrm{NO}_{6} \mathrm{P}_{2}: \mathrm{C}$, 30.55; H, 6.96; and N, 5.09. Found: C, 29.74; H, 6.91; and N, 5.02 .

[(Hexylimino)bis(methylene)]bis(phosphonic acid) (5) was prepared following the same procedure. Around $1 \mathrm{~h}$, after starting the refluxing, brown solid started forming into the solution. After cooling down and stirring the solution for $\sim 15$ min, white solid precipitated heavily out, and it was isolated by suction filtration. The crude product contained still some brown impurities, which were removed by dissolving the product in hot water and filtrating while hot. The crude product was purified by recrystallization from hot water, and colorless needles were obtained. Yield $6.36 \mathrm{~g}, 36 \% .{ }^{1} \mathrm{H}$ NMR $\left(\mathrm{D}_{2} \mathrm{O} 300 \mathrm{MHz}\right): \delta 3.71-3.50(\mathrm{~m}, 6 \mathrm{H}), 1.84(\mathrm{~m}, 2 \mathrm{H}), 1.52-$ $1.29(\mathrm{~m}, 6 \mathrm{H})$, and $0.93(\mathrm{t}, 3 \mathrm{H}) .{ }^{31} \mathrm{P}$ NMR $\left(\mathrm{D}_{2} \mathrm{O} 300 \mathrm{MHz}\right): \delta$ 8.66. Elemental analysis calcd for $\mathrm{C}_{8} \mathrm{H}_{21} \mathrm{NO}_{6} \mathrm{P}_{2}$ : C, 33.22; $\mathrm{H}$, 7.32; and N, 4.84. Found: C, 32.79; H, 7.23; and N, 4.82.

[(2-Ethylhexylimino)bis(methylene) $]$ bis(phosphonic acid) (6) was prepared by refluxing the reaction mixture for $3 \mathrm{~h}$ instead of $12 \mathrm{~h}$ at $120{ }^{\circ} \mathrm{C}$. The solution was concentrated and the left stand at the room temperature overnight. The precipitated white solid was filtrated, washed with cold water, and purified by recrystallization from hot water. Yield $11.46 \mathrm{~g}$, 46\%. ${ }^{1} \mathrm{H}$ NMR $\left(\mathrm{D}_{2} \mathrm{O} 300 \mathrm{MHz}\right): \delta 3.61(\mathrm{~d}, 4 \mathrm{H}), 3.54(\mathrm{~m}$, $2 \mathrm{H}), 1.98(\mathrm{~m}, 1 \mathrm{H}), 1.59-1.29(\mathrm{~m}, 8 \mathrm{H})$, and $0.95(\mathrm{~m}, 6 \mathrm{H}) .{ }^{31} \mathrm{P}$ NMR $\left(\mathrm{D}_{2} \mathrm{O} 300 \mathrm{MHz}\right): \delta 8.37$. Elemental analysis calc. (\%): $\mathrm{N}: 4.42$, C: 37.86, and $\mathrm{H}: 7.94$; meas. (\%): $\mathrm{N}: 4.173$, C: 37.12, and $\mathrm{H}$ : 7.972. Elemental analysis calcd for $\mathrm{C}_{10} \mathrm{H}_{25} \mathrm{NO}_{6} \mathrm{P}_{2}$ : C, 37.86; H, 7.94; and N, 4.42. Found: C, 37.12; H, 7.97; and N, 4.17.

Deprotonation Titration. Three hundred milligrams of 1 was dissolved into $9 \mathrm{~mL}$ of $\mathrm{D}_{2} \mathrm{O}$ to obtain a $0.14 \mathrm{M}$ solution. Nondeuterated $5 \% \mathrm{NH}_{3}$ solution was added to the stock solution, and from each $0.5 \mathrm{pH}$, the NMR sample was taken aside. The $\mathrm{pH}$ was measured in the range of 0.5 to 10.5 .

NMR Titrations. Titrating 1 with $\mathrm{Y}\left(\mathrm{NO}_{3}\right)_{3}: 0.01 \mathrm{M}$ solution of ligand $\mathbf{1}$ was prepared by dissolving ligand $\mathbf{1}$ (10.249 mg, $0.044 \mathrm{mmol}$ ) into $4.4 \mathrm{~mL}$ of $\mathrm{D}_{2} \mathrm{O}$. Typically, 0.6 $\mathrm{mL}$ of analyte was taken aside, and roughly 20 times excess of $\mathrm{Y}\left(\mathrm{NO}_{3}\right)_{3} \cdot 6 \mathrm{H}_{2} \mathrm{O}(303.07 \mathrm{mg}, 0.791 \mathrm{mmol})$ was added to the titrant. The analyte was titrated by adding 0.1 equiv of the titrant $(4 \mu \mathrm{L})$ to the analyte, and ${ }^{31} \mathrm{P}$ NMR spectra was measured after each addition. The analyte was titrated until the concentration reached 1 equiv. Titrations were performed similarly with $\mathrm{La}\left(\mathrm{NO}_{3}\right)_{3}$ and $\mathrm{Lu}\left(\mathrm{NO}_{3}\right)_{3}$ by preparing $0.01 \mathrm{M}$ solution of 1 into $3 \mathrm{~mL}$ of $\mathrm{D}_{2} \mathrm{O}$, taking $0.6 \mathrm{~mL}$ analyte aside and adding excess $\mathrm{La}\left(\mathrm{NO}_{3}\right)_{3}(88.00 \mathrm{mg}, 0.203 \mathrm{mmol})$ or $\mathrm{Lu}\left(\mathrm{NO}_{3}\right)_{3}(61.64 \mathrm{mg}, 0.17 \mathrm{mmol})$ into the titrant. Analyte was titrated by adding 0.1 equiv $(10 \mu \mathrm{L})$ to the titrant until 1 equiv was reached. $\mathrm{pH}$ for the $\mathrm{Lu}$ titration was set to 1.0 to prevent the complex from precipitating. All titrations were replicated three times.

Titrating $\mathrm{Y}\left(\mathrm{NO}_{3}\right)_{3}, \mathrm{La}\left(\mathrm{NO}_{3}\right)_{3}$ with 1: Titrations were done by following the same procedure. The analyte was titrated by adding 0.3 equiv of the titrant $(7 \mu \mathrm{L})$ to the analyte until the concentration reached 5 equiv.

All titrations were replicated three times and $\mathrm{pH}$ was monitored during titrations. Binding models were fitted with HypNMR2008 programme Version 4.0.71..$^{50}$

Precipitation Experiments. Two hundred fifty milligrams of ligands 1-6 were dissolved into $100 \mathrm{~mL}$ of $5 \% \mathrm{HNO}_{3}$ prepared from ultrapure water to avoid any unwanted element contaminations. Typically, $1 \mathrm{~g} / \mathrm{L}$ uranium standard solution was diluted $\left(10 / 100 \mathrm{~mL} 5 \% \mathrm{HNO}_{3}\right)$ to obtain $100 \mathrm{mg} / \mathrm{L}$ solution, and $1.7 \mathrm{~mL}$ of the solution was combined with 17.3 $\mathrm{mL}$ of the $10 \mathrm{mg} / \mathrm{L}$ REE multistandard solution (Ln, Sc, Y, $\mathrm{Th}$ ) to obtain roughly $9 \mathrm{mg} / \mathrm{L}$ solution for the inspected

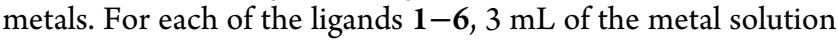
and $3 \mathrm{~mL}$ of the ligand solution were combined and $\mathrm{pH}$ was set with $5 \% \mathrm{NH}_{3}$, prepared in ultrapure water. From each $\mathrm{pH}$ increment of 0.5 in the $\mathrm{pH}$ range of $1-4$, and before adding ammonia ( $\mathrm{pH} 0$ ), $0.5 \mathrm{~mL}$ of the sample was taken aside, filtrated with syringe, and diluted to $5 \mathrm{~mL}$ with $5 \% \mathrm{HNO}_{3}$ for the ICP-OES measurements. The measurements were replicated three times. Precipitation experiments were also performed for the solutions without ligands $1-6$, to investigate the precipitation of metals in the absence of ligands.

Ligand Recovery. Roughly $0.01 \mathrm{M}$ solution of the 1:3 metal-ligand complex of $\mathrm{Y}$ with 1 was prepared by dissolving $16.45 \mathrm{mg}$ of 1 and $9.07 \mathrm{mg}$ of $\mathrm{Y}\left(\mathrm{NO}_{3}\right)_{3}$ into $6 \mathrm{~mL}$ of $\mathrm{D}_{2} \mathrm{O}$. The $\mathrm{pH}$ of the solution was set with $65 \% \mathrm{HNO}_{3}$, and samples were taken from the solution every 0.5 change in $\mathrm{pH}$ within the $\mathrm{pH}$ range of 1.5 to -1 . For comparision, roughly $0.01 \mathrm{M}$ solution of free ligand 1 was prepared by dissolving $4.97 \mathrm{mg}$ of 1 into the $1-2 \mathrm{~mL}$ of $\mathrm{D}_{2} \mathrm{O}$. $\mathrm{pH}$ was set similarly with $65 \% \mathrm{HNO}_{3}$ and samples were taken aside every $0.5 \mathrm{pH} .{ }^{31} \mathrm{P}$ NMR spectra of each sample were measured.

Computational Details. The lowest energy structure for the $1: 3$ complex of $\mathrm{Y}^{3+}$ and three $[\mathrm{L} 1]^{-}$in the neutral and zwitterionic form was obtained from the conformational sampling, which were followed by the three different separate DFT calculations. The conformational sampling was carried out employing the Merck Molecular Force Field (MMFF) ${ }^{51}$ with Monte-Carlo search as implemented in Spartan' 18 molecular modeling software. ${ }^{52}$ The same software was also used in the subsequent PBE-D3/def2-SV $(P)^{53-59}$ single-point energy calculations that were carried out for all 1483 and 901 unique structures of neutral and zwitterionic forms, respectively, obtained from the conformational sampling. Out of these structures, 277 (198) lowest energy structures of the neutral (zwitterionic) form were selected to the full geometry optimizations performed at the PBE1PBE-D3/def2-SV$(\mathrm{P})^{57-61}$ level of theory in the gas-phase because no clear energy cut-off value could be determined from the results of the single-point energy calculations. These calculations were carried out with Gaussian 16 quantum chemistry program. ${ }^{62}$ For both forms, the subsequent final geometry optimizations were performed for the 10 lowest energy structures obtained from the previous step at the PBE1PBE-D3/def2-TZVP ${ }^{57-61}$ 
level in a solution state. In the solution-state calculations, water was used as a solvent and it was modeled using the integral equation formalism variant of the polarizable continuum model as implement in the Gaussian $16^{63-66}$ The frequency analyses were calculated for all of the final optimized structures to ensure that they correspond to a true minimum on the potential energy hypersurface (no negative frequencies).

\section{ASSOCIATED CONTENT}

\section{(s) Supporting Information}

The Supporting Information is available free of charge at https://pubs.acs.org/doi/10.1021/acsomega.1c02982.

Characterization for the aminobis(phosphonates) 1-6 $\left({ }^{1} \mathrm{H}\right.$ NMR and IR spectra) NMR titration curve for ligand 1, spectra, and plotted shifts for the complexation studies; Tables for the separation factors between adjacent lanthanoids and ${ }^{31} \mathrm{P}$ NMR spectra for the ligand recovery (PDF)

\section{AUTHOR INFORMATION}

\section{Corresponding Authors}

Ari Väisänen - Department of Chemistry, University of Jyväskylä, FI-40014 Jyväskylä, Finland;

Email: ari.o.vaisanen@jyu.fi

Jani O. Moilanen - Department of Chemistry, Nanoscience Center, University of Jyväskylä, FI-40014 Jyväskylä, Finland; 다이.org/0000-0002-2096-593X;

Email: jani.o.moilanen@jyu.fi

\section{Authors}

Emilia J. Virtanen - Department of Chemistry, Nanoscience Center, University of Jyväskylä, FI-40014 Jyväskylä, Finland

Siiri Perämäki - Department of Chemistry, University of Jyväskylä, FI-40014 Jyväskylä, Finland; 이이.org/00000002-3983-186X

Kaisa Helttunen - Department of Chemistry, Nanoscience Center, University of Jyväskylä, FI-40014 Jyväskylä, Finland; (1) orcid.org/0000-0001-7455-4207

Complete contact information is available at: https://pubs.acs.org/10.1021/acsomega.1c02982

\section{Author Contributions}

All authors have given approval to the final version of the manuscript.

\section{Notes}

The authors declare no competing financial interest.

\section{ACKNOWLEDGMENTS}

The authors would like to acknowledge the financial support provided by the University of Jyväskylä and the Academy of Finland (projects 315829, 320015, 309910, 314287). CSC-IT Center for Science in Finland, the Finnish Grid and Cloud Infrastructure (persistent identifier urn:nbn:fi:research-infras2016072533), and Prof. H. M. Tuononen (University of Jyväskylä) are acknowledged for providing computational resources for the project. Laboratory engineering Elina Hautakangas is acknowledged for carrying out elemental analyses for the samples.

\section{REFERENCES}

(1) Balaram, V. Rare earth elements: A review of applications, occurrence, exploration, analysis, recycling, and environmental impact. Geosci. Front. 2019, 10, 1285-1303.

(2) Bobba, S.; Carrara, S.; Huisman, J.; Mathieux, F.; Pavel, C. Critical Raw Materials for Strategic Technologies and Sectors in the EUa Foresight Study; European Commission, 2020.

(3) Goodenough, K. M.; Wall, F.; Merriman, D. The Rare Earth Elements: Demand, Global Resources, and Challenges for Resourcing Future Generations. Nat. Resour. Res. 2018, 27, 201-216.

(4) Gupta, C. K.; Krishnamurthy, N. Extractive Metallurgy of Rare Earths; CRC Press, 2005.

(5) Borra, C. R.; Pontikes, Y.; Binnemans, K.; Van Gerven, T. Leaching of rare earths from bauxite residue (red mud). Miner. Eng. 2015, 76, 20-27.

(6) Buechler, D. T.; et al. Comprehensive elemental analysis of consumer electronic devices: Rare earth, precious, and critical elements. Waste Manage. 2020, 103, 67-75.

(7) Binnemans, K.; et al. Recycling of rare earths: A critical review. J. Cleaner Prod. 2013, 51, 1-22.

(8) Zhu, Z.; Pranolo, Y.; Cheng, C. Y. Separation of uranium and thorium from rare earths for rare earth production - A review. Miner. Eng. 2015, 77, 185-196.

(9) Sun, X.; Waters, K. E. Synergistic effect between bifunctional ionic liquids and a molecular extractant for lanthanide separation. ACS Sustainable Chem. Eng. 2014, 2, 2758-2764.

(10) Guo, L.; et al. Highly Selective Extraction and Separation of Rare Earths(III) Using Bifunctional Ionic Liquid Extractant. ACS Sustainable Chem. Eng. 2014, 2, 1968-1975.

(11) Sun, P.; Huang, K.; Song, W.; Gao, Z.; Liu, H. Separation of Rare Earths from the Transition Metals Using a Novel Ionic-LiquidBased Aqueous Two-Phase System: Toward Green and Efficient Recycling of Rare Earths from the NdFeB Magnets. Ind. Eng. Chem. Res. 2018, 57, 16934-16943.

(12) Vargas, S. J. R.; Quintão, J. C.; Ferreira, G. M. D.; Da Silva, L. H. M.; Hespanhol, M. C. Lanthanum and Cerium Separation Using an Aqueous Two-Phase System with Ionic Liquid. J. Chem. Eng. Data 2019, 64, 4239-4246.

(13) He, Y.; et al. "Super moiety"-phosphoramidate in task-specific ionic liquids for effcient thorium separation through hybrid interaction. Sep. Purif. Technol. 2020, 252, No. 117466.

(14) Prodius, D.; et al. Rationally designed rare earth separation by selective oxalate solubilization. Chem. Commun. 2020, 56, 1138611389.

(15) Yin, X.; et al. Rare earth separations by selective borate crystallization. Nat. Commun. 2017, 8, No. 14438.

(16) Tasaki-Handa, Y.; et al. Separation of neodymium and dysprosium by forming coordination polymers. Sep. Purif. Technol. 2016, 157, 162-168.

(17) Tasaki-Handa, Y.; et al. Selective Crystallization of Phosphoester Coordination Polymer for the Separation of Neodymium and Dysprosium: A Thermodynamic Approach. J. Phys. Chem. B 2016, 120, 12730-12735.

(18) Lu, H.; et al. Size-dependent selective crystallization using an inorganic mixed-oxoanion system for lanthanide separation. Dalton Trans. 2019, 48, 12808-12811.

(19) Wang, Y.; et al. Facile and Efficient Decontamination of Thorium from Rare Earths Based on Selective Selenite Crystallization. Inorg. Chem. 2018, 57, 1880-1887.

(20) Galezowska, J.; Gumienna-Kontecka, E. Phosphonates, their complexes and bio-applications: A spectrum of surprising diversity. Coord. Chem. Rev. 2012, 256, 105-124.

(21) Amoroso, A. J.; Fallis, I. A.; Pope, S. J. A. Chelating agents for radiolanthanides: Applications to imaging and therapy. Coord. Chem. Rev. 2017, 340, 198-219.

(22) Zhao, Q.; et al. Synergistic extraction of heavy rare earths by mixture of $\alpha$-aminophosphonic acid HEHAMP and HEHEHP. J. Rare Earths 2019, 37, 422-428. 
(23) Kuang, S.; Zhang, Z.; Li, Y.; Wei, H.; Liao, W. Extraction and separation of heavy rare earths from chloride medium by $\alpha$ aminophosphonic acid HEHAPP. J. Rare Earths 2018, 36, 304-310.

(24) Wei, H.; Li, Y.; Zhang, Z.; Liao, W. Synergistic solvent extraction of heavy rare earths from chloride media using mixture of HEHHAP and Cyanex272. Hydrometallurgy 2020, 191, No. 105240.

(25) Wei, H.; Li, Y.; Kuang, S.; Zhang, Z.; Liao, W. Separation of trivalent rare earths from chloride medium using solvent extraction with heptylaminomethyl phosphonic acid 2-ethylhexyl ester (HEHHAP). Hydrometallurgy 2019, 188, 14-21.

(26) Kuang, S.; Zhang, Z.; Li, Y.; Wei, H.; Liao, W. Synergistic extraction and separation of rare earths from chloride medium by the mixture of HEHAPP and D2EHPA. Hydrometallurgy 2017, 174, 7883.

(27) Lu, Y.; Zhang, Z.; Li, Y.; Liao, W. Extraction and recovery of cerium(IV) and thorium(IV) from sulphate medium by an $\alpha$ aminophosphonate extractant. J. Rare Earths 2017, 35, 34-40.

(28) Moedritzer, K.; Irani, R. R. The Direct Synthesis of $\alpha$ Aminomethylphosphonic Acids. Mannich-Type Reactions with Orthophosphorous Acid. J. Org. Chem. 1966, 31, 1603-1607.

(29) Gift, A. D.; Stewart, S. M.; Kwete Bokashanga, P. Experimental determination of $\mathrm{pK}$ a values by use of NMR chemical shifts, revisited. J. Chem. Educ. 2012, 89, 1458-1460.

(30) Lide, D. R. CRC Handbook of Chemistry and Physics; CRC Press, 2004.

(31) Kubíček, V.; Kotek, J.; Hermann, P.; Lukeš, I. Aminoalkylbis(phosphonates): Their complexation properties in solution and in the solid state. Eur. J. Inorg. Chem. 2007, 2007, 333-344.

(32) Boichenko, A. P.; Markov, V. V.; Kong, H.; Matveeva, A. G.; Loginova, L. P. Re-evaluated data of dissociation constants of alendronic, pamidronic and olpadronic acids. Open Chem. 2009, 7, $8-13$.

(33) David, T.; et al. Aminoalkyl-1,1-bis(phosphinic acids): Stability, Acid-Base, and Coordination Properties. Eur. J. Inorg. Chem. 2014, 2014, 4357-4368.

(34) Nash, K. L. The Chemistry of TALSPEAK: A Review of the Science. Solvent Extr. Ion Exch. 2015, 33, 1-55.

(35) Mathur, J. N. Extraction of thorium with 2-ethyl hexyl phosphonic acid mono-2- ethyl hexyl ester (PC-88A). J. Radioanal. Nucl. Chem. 2001, 250, 123-128.

(36) Bazaga-García, M.; et al. Luminescent and Proton Conducting Lanthanide Coordination Networks Based on a Zwitterionic Tripodal Triphosphonate. Inorg. Chem. 2016, 55, 7414-7424.

(37) Cunha-Silva, L.; et al. Photoluminescent lanthanide-organic 2D networks: A combined synchrotron powder X-ray diffraction and solid-state NMR study. Chem. Mater. 2007, 19, 3527-3538.

(38) Das, D.; Brahmmananda Rao, C. V. S.; Sivaraman, N.; Sivaramakrishna, A.; Vijayakrishna, K. Synthesis and extraction behavior of alkyl and cyclic aminophosphonates towards actinides. Inorg. Chim. Acta 2018, 482, 597-604.

(39) Goud, E. V.; et al. Unexpected Coordination Modes of Bisphosphoramides with Lanthanum(III) and Thorium(IV) Salts: Synthesis, Structural Characterization, Stability, and Extraction Studies. ChemistrySelect 2021, 6, 2085-2093.

(40) Reed, W. A.; et al. Complexation of UVI with 1-hydroxyethane1,1-diphosphonic acid in acidic to basic solutions. Inorg. Chem. 2007, $46,2870-2876$.

(41) Jacopin, C.; et al. Investigation of the interaction between 1hydroxyethane-1,1'-diphosphonic acid (HEDP) and uranium(VI). Inorg. Chem. 2003, 42, 5015-5022.

(42) Wu, Q. Y.; Wang, C. Z.; Lan, J. H.; Chai, Z. F.; Shi, W. Q. Theoretical insight into the binding affinity enhancement of serine with the uranyl ion through phosphorylation. RSC Adv. 2016, 6, 69773-69781.

(43) Sadeghi, M. H.; Outokesh, M.; Zare, M. H. Production of high quality ammonium uranyl carbonate from "uranyl nitrate + carbonate" precursor solution. Prog. Nucl. Energy 2020, 122, No. 103270.
(44) Mellah, A.; Chegrouche, S.; Barkat, M. The precipitation of ammonium uranyl carbonate (AUC): Thermodynamic and kinetic investigations. Hydrometallurgy 2007, 85, 163-171.

(45) Battsengel, A.; et al. Recovery of light and heavy rare earth elements from apatite ore using sulphuric acid leaching, solvent extraction and precipitation. Hydrometallurgy 2018, 179, 100-109.

(46) Tunsu, C.; Petranikova, M.; Ekberg, C.; Retegan, T. A hydrometallurgical process for the recovery of rare earth elements from fluorescent lamp waste fractions. Sep. Purif. Technol. 2016, 161, $172-186$.

(47) Suzuki, Y.; Nagayama, T.; Sekine, M.; Mizuno, A.; Yamaguchi, K. Precipitation incidence of the lanthanoid(III) hydroxides. J. LessCommon Met. 1986, 126, 351-356.

(48) Nelson, J. J. M.; et al. High-throughput screening for discovery of benchtop separations systems for selected rare earth elements. Commun. Chem. 2020, 3, No. 7.

(49) Weaver, B. Fractional Separation of Rare Earths by Oxalate Precipitation from Homogeneous Solution. Anal. Chem. 1954, 26, 479-480.

(50) Frassineti, C.; et al. Nuclear magnetic resonance as a tool for determining protonation constants of natural polyprotic bases in solution. Anal. Biochem. 1995, 231, 374-382.

(51) Halgren, T. A. Force Fields for Conformational Interaction Energies and Geometries. J. Comput. Chem. 1999, 20, 730-748.

(52) Spartan 18; Wavefunction Inc.: Irvivine CA, 2019.

(53) Perdew, J. P.; Burke, K.; Ernzerhof, M. Generalized gradient approximation made simple. Phys. Rev. Lett. 1996, 77, 3865-3868.

(54) Perdew, J. P.; Wang, Y. Accurate and simple analytic representation of the electron-gas correlation energy. Phys. Rev. B 1992, 45, 13244-13249.

(55) Grimme, S.; Antony, J.; Ehrlich, S.; Krieg, H. A consistent and accurate $a b$ initio parametrization of density functional dispersion correction (DFT-D) for the 94 elements H-Pu. J. Chem. Phys. 2010, 132, No. 241733.

(56) Grimme, S.; Ehrlich, S.; Goerigk, L. Effect of the damping function in dispersion corrected density functional theory. J. Comput. Chem. 2011, 32, 1456-1465.

(57) Andrae, D.; Häußermann, U.; Dolg, M.; Stoll, H.; Preuß, H. Energy-adjusted $\mathrm{ab}$ initio pseudopotentials for the second and third row transition elements. Theor. Chim. Acta 1990, 77, 123-141.

(58) Weigend, F. Hartree-fock exchange fitting basis sets for $\mathrm{H}$ to Rn. J. Comput. Chem. 2008, 29, 167-175.

(59) Weigend, F.; Ahlrichs, R. Balanced basis sets of split valence, triple zeta valence and quadruple zeta valence quality for $\mathrm{H}$ to $\mathrm{Rn}$ : Design and assessment of accuracy. Phys. Chem. Chem. Phys. 2005, 7, $3297-3305$.

(60) Ernzerhof, M.; Scuseria, G. E. Assessment of the Perdew-BurkeErnzerhof exchange-correlation functional. J. Chem. Phys. 1999, 110, 5029-5036.

(61) Adamo, C.; Barone, V. Toward reliable density functional methods without adjustable parameters: The PBE0 model. J. Chem. Phys. 1999, 110, 6158-6170.

(62) Frisch, M. J.; Trucks, G. W.; Schlegel, H. B.; Scuseria, G. E.; Robb, M. A.; Cheeseman, J. R.; Scalmani, G.; Barone, V.; Petersson, G. A.; Nakatsuji, H.; Li, X.; Caricato, M.; Marenich, A. V.; Bloino, J.; Janesko, B. G.; Gomperts, R.; Mennucci, B.; Hratchian, H. P.; Farkas, J. B.; Foresman, J. V.; Fox, D. J. et al. Gaussian 16; Gaussian, Inc.: Wallingford CT, 2016.

(63) Miertuš, S.; Scrocco, E.; Tomasi, J. Electrostatic interaction of a solute with a continuum. A direct utilizaion of $\mathrm{AB}$ initio molecular potentials for the prevision of solvent effects. Chem. Phys. 1981, 55, 117-129.

(64) Pascual-ahuir, J. L.; Silla, E.; Tuñon, I. GEPOL: An improved description of molecular surfaces. III. A new algorithm for the computation of a solvent-excluding surface. J. Comput. Chem. 1994, $15,1127-1138$.

(65) Miertus̃, S.; Tomasi, J. Approximate evaluations of the electrostatic free energy and internal energy changes in solution processes. Chem. Phys. 1982, 65, 239-245. 
(66) Tomasi, J.; Mennucci, B.; Cancès, E. The IEF version of the PCM solvation method: An overview of a new method addressed to study molecular solutes at the QM ab initio level. J. Mol. Struct.: THEOCHEM 1999, 464, 211-226. 